\title{
G. J. Brierley and K. A. Fryirs, River Futures: An integrative scientific approach to river repair
}

\author{
Island Press, Washington, DC, 2008, 325 pp, $26 \mathrm{~cm}$; maps, figures, \\ ISBN-13:978-1-59726-112-8 (cloth), ISBN-13:978-1-59726-113-5 (paper)
}

\author{
Janine Bolliger
}

Received: 29 August 2008/Accepted: 11 September 2008/Published online: 25 September 2008

(C) Springer Science+Business Media B.V. 2008

Humans have significantly changed aquatic ecosystems throughout the world. Growing awareness of human-induced change has caused a shift in management programs towards strategies to restore rivers. The book entitled "River Futures" by Gary J. Brierley and Kirstie A. Fryirs provides an essential overview over scientific, social, cultural, and economic avenues towards more natural river systems. The book is richly illustrated with case studies and examples across the world.

The book was written with the purpose to foster direct collaboration between scientists, stakeholders, managers, decision makers, and the broad public who value efforts to restore river systems. Since jargon is minimised, the book is accessible to a broad audience including science students, river managers, consultants, resource managers, and environmentalists. The book is structured into four parts with each part containing two to six chapters.

Part I describes the emerging process of river repair. River repair relies on a paradigm shift from engineering river systems primarily for human purposes towards an ecosystem perspective which aims at balancing human needs with environmental and sustainability values. This approach maximises biodiversity and sustainability foci while accounting for

J. Bolliger $(\bowtie)$

Swiss Federal Research Institute WSL, Zürcherstrasse

111, 8903 Birmensdorf, Switzerland

e-mail: janine.bolliger@wsl.ch ecosystem services. Visions and challenges on this topic are outlined in three chapters.

Part II discusses crossdisciplinary scientific considerations which relate to river repair, measures to identify river conditions, and assessments on the societal relations to river systems. Abiotic conditions and structural functions are merged with ecological considerations and functional relationships to achieve a whole-system approach to river repair. Additionally, spatial properties of river systems are addressed and relate them to the catchment focus of river repair which relies on lateral, longitudinal and vertical linkages in river systems. Finally, the integrative topic of connectivity is used to assess biophysical properties and ecosystem connectivity with social values of river repair. Combined, this information provides an integrative scientific platform which enable assessments on the river restoration potential of a given catchment.

Part III exemplifies current avenues in river repair by relying on case studies originating from Australia, USA, Europe, Japan, and South Africa. Common trends across the world include a growing awareness of the importance of ecosystem values which increasingly rely on crossdisciplinary approaches to manage river systems. Differences among case studies in river repair primarily originate from socio-economic and cultural values, as well as from variation in disturbance and management history among the various biophysical backgrounds.

Part IV addresses various sources of uncertainties which are related to system restoration. The complexity 
of social and ecological systems reveals that accurate cause-and-effect predictions for a certain state at a particular time are not feasible. This uncertainty, however, does not imply weakness of the approaches. Rather, planning for resilience will allow systems to have a greater ability to deal with and recover from unanticipated events. This adaptive capacity is considered key when dealing with vulnerability and risk.

Overall, this book gives a unique overview of the current state of knowledge on river rehabilitation. The book is comprehensively written and well organised. The book is easy to read, and the language is partly colloquial. River repair, a term frequently used in the book, contains a strong anthropocentric component which demonstrates the human ability to alter largescale ecosystems to a state close to what we might consider natural. This capacity, however, is nicely set off by the chapter on uncertainties which are associated with restoring complex social and ecological systems (Chap. 14). 